\title{
A Robust Fuzzy Sliding Mode Controller Synthesis Applied on Boost DC-DC Converter Power Supply for Electric Vehicle Propulsion System
}

\author{
Boumediène Allaoua, Brahim Mebarki, and Abdellah Laoufi \\ Faculty of the Sciences and Technology, Bechar University, BP 417, 08000 Bechar, Algeria \\ Correspondence should be addressed to Boumediène Allaoua; elec_allaoua2bf@yahoo.fr
}

Received 12 March 2013; Revised 3 May 2013; Accepted 7 May 2013

Academic Editor: Aboelmagd Noureldin

Copyright (C) 2013 Boumediène Allaoua et al. This is an open access article distributed under the Creative Commons Attribution License, which permits unrestricted use, distribution, and reproduction in any medium, provided the original work is properly cited.

The development of electric vehicles power electronics system control comprising of DC-AC inverters and DC-DC converters takes a great interest of researchers in the modern industry. A DC-AC inverter supplies the high power electric vehicle motors torques of the propulsion system and utility loads, whereas a DC-DC converter supplies conventional low-power, low-voltage loads. However, the need for high power bidirectional DC-DC converters in future electric vehicles has led to the development of many new topologies of DC-DC converters. Nonlinear control of power converters is an active area of research in the fields of power electronics. This paper focuses on a fuzzy sliding mode strategy (FSMS) as a control strategy for boost DC-DC converter power supply for electric vehicle. The proposed fuzzy controller specifies changes in the control signal based on the surface and the surface change knowledge to satisfy the sliding mode stability and attraction conditions. The performances of the proposed fuzzy sliding controller are compared to those obtained by a classical sliding mode controller. The satisfactory simulation results show the efficiency of the proposed control law which reduces the chattering phenomenon. Moreover, the obtained results prove the robustness of the proposed control law against variation of the load resistance and the input voltage of the studied converter.

\section{Introduction}

Electric vehicles power management has an important role, as it has the ability to decide the electric vehicle power status in efficient economy. Power management is the way in which energy is moved to and from the energy storage device and the electric motor and includes the quantity of energy and the time over which it is done $[1,2]$.

A lot of researchers and several papers use a constant energy source alimentation to walk their electric vehicles, which does not exist in reality because all batteries have proper autonomous which depend on their specific energy storage (state of charge and depth of discharge) where the output voltage is not constant $[3,4]$. For this reason, we use the DCDC converter with a control strategy to assure the energy requirement for the electric vehicle and the propulsion system. Consequently, the proposed control strategy applied on DC-DC converter assures and maintains the DC output voltage constant against load variations to satisfy the inputs electric vehicle inverter demand.

Energy storage or power supply devices vary their output voltage with load or state of charge, and this creates major challenges for electric vehicle designers when integrating energy storage or power supply devices with a traction drive $[2,4]$. DC-DC converters can be used to interface the elements in the electric power train by boosting or chopping the voltage levels [5], but their use is limited due to the size, weight, efficiency, and cost of current boost DC-DC converter [6, 7]. Recent applications in the design of power supply employ boost DC-DC converters because the required output is inverted directly from the input voltage, and the output voltage can be either higher or lower than the input voltage $[6,8]$. The boost power converters are widely used in applications like automotive and marine.

A boost DC-DC converter with robust control strategy used in battery electric vehicles must provide a regulated DC 


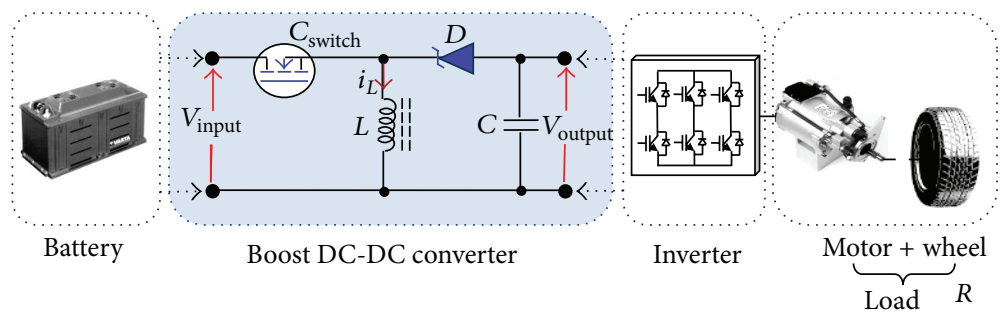

FIGURE 1: Studied boost converter structure for the electric vehicle drive.

output voltage when varying load, or when the input voltage varies, if the battery state of charge varies $[8,9]$. Generally, the linear conventional control solutions applied to power electronic system, especially for boost DC-DC converter, failed to accomplish robustness under nonlinearity, parameter variation, load disturbance, and input voltage variation. As a result, there is more interest in developing more nonlinear and advanced nonconventional robust control structures to improve the performance of the boost DC-DC converter $[9,10]$.

The fuzzy sliding mode strategy (FSMS) has been proposed to improve the robustness and the dynamic response in switch mode power supplies. The FSMS is a control approach, which complies with the nonlinear nature of switch-mode power supplies. This control technique offers several advantages compared to traditional control methods: stability, even for large line and load variations, robustness, and good dynamic response $[11,12]$. The output voltage and its derivative are both continuous and accessible for measurement. Before going forward for applying FSMS to switch mode power supply, let us take a brief look on the theory of FSMS.

Fuzzy logic control and sliding mode control (SMC) have been combined in a variety of ways for sliding surface design $[13,14]$. These approaches can be classified into two categories. The first approach taken by many researchers is to use fuzzy logic control for the determination of the sliding surface movement of the classical SMC [14, 15]. A Takagi-Sugeno type fuzzy tuning algorithm is used for the movement of the sliding surface [16-18]. The objective of the second approach is to determinate directly the sliding surface based on fuzzy logic; this method is called fuzzy sliding mode strategy.

This paper proposes a robust fuzzy sliding mode strategy to control the boost DC-DC converter power supply target for electric vehicle applications. In this scheme, a fuzzy sliding mode controller is investigated, in which the fuzzy logic system is used to replace the discontinuous control action of the classical SMC law to improve the DC output voltage performance of the boost DC-DC converter. The results obtained are compared with the ones achieved with a classical SMC in terms of start-up behavior and robustness to disturbances.

\section{Boost DC-DC Converter for Electric Vehicle}

Boosts DC-DC converters find applications in places where battery charging, regenerative braking, and backup power are required. The power flow in a bidirectional converter is usually from a low voltage end, such as battery or a super capacitor, to a high voltage side and is referred to as boost operation $[3,19]$.

An electric vehicle boost converter provides an output voltage which can be higher or lower than the battery input voltage $[3,20,21]$. The output voltage polarity is opposite to that of the input voltage. Figure 1 shows a simplified structure of the boost converter associated with electrical vehicle drive. It consists of a battery DC input voltage source $\left(V_{\text {input }}\right), \mathrm{DC}$ output voltage $\left(V_{\text {output }}\right)$ delivered to the electric vehicle drive, a controlled switch $\left(C_{\text {switch }}\right)$, a diode $(D)$, a filter inductor $(L)$, a filter capacitor $(C)$, and a load resistance $(R)$.

During the normal operation of the boost power stage, $\left(C_{\text {switch }}\right)$ is repeatedly switched ON and OFF with the on and off times under the control of the duty ratio. Depending on whether the switch $\left(C_{\text {switch }}\right)$ is ON or OFF, the converter operation can be divided into two modes of operation. During mode - I- the switch $\left(C_{\text {switch }}\right)$ is conducting electricity and during second mode the switch $\left(C_{\text {switch }}\right)$ is open. When the switch is $\mathrm{ON}$ the system is linear, and the state space equations can be written as follows:

$$
\begin{aligned}
\frac{d i_{L}}{d t} & =\frac{1}{L} V_{\text {input }}, \\
\frac{d V_{\text {output }}}{d t} & =-\frac{1}{R C} V_{\text {output }},
\end{aligned}
$$

where the state variables are the inductance currents $\left(i_{L}\right)$ and capacitance voltages $\left(V_{\text {output }}\right)$.

When the switch is OFF the system is also linear, and the state space equations are given by

$$
\begin{gathered}
\frac{d i_{L}}{d t}=\frac{1}{L} V_{\text {output }} \\
\frac{d V_{\text {output }}}{d t}=-\frac{1}{C} i_{L}-\frac{1}{R C} V_{\text {output }}
\end{gathered}
$$

The choice of the state vector $x=\left[\begin{array}{l}x_{\mathrm{I}} \\ x_{\text {II }}\end{array}\right]=\left[\begin{array}{c}i_{L} \\ V_{\text {output }}\end{array}\right]$ allows the state space representation for mode - I- by

$$
\begin{gathered}
\dot{x}_{\mathrm{I}}=A_{\mathrm{I}} \cdot x+B_{\mathrm{I}} \cdot u, \\
V_{\text {output }}=C_{\mathrm{I}} \cdot x,
\end{gathered}
$$

where $A_{\mathrm{I}}=\left[\begin{array}{cc}0 & 0 \\ 0 & -1 / R C\end{array}\right], B_{\mathrm{I}}=\left[\begin{array}{c}1 / L \\ 0\end{array}\right], C_{\mathrm{I}}=\left[\begin{array}{ll}0 & 1\end{array}\right]$, and $u=$ $V_{\text {input }}$. 
And it follows the state space representation for mode II- by

$$
\begin{gathered}
\dot{x}_{\mathrm{II}}=A_{\mathrm{II}} \cdot x+B_{\mathrm{II}} \cdot u, \\
V_{\text {output }}=C_{\mathrm{II}} \cdot x,
\end{gathered}
$$

where $A_{\mathrm{II}}=\left[\begin{array}{cc}0 & 1 / L \\ -1 / C & -1 / R C\end{array}\right], B_{\mathrm{II}}=\left[\begin{array}{l}0 \\ 0\end{array}\right], C_{\mathrm{II}}=\left[\begin{array}{ll}0 & 1\end{array}\right]$, and $u=$ $V_{\text {input }}$.

The state space averaging method replaces the state equations by a single state space description which represents approximately the behavior of the circuit across the whole period. From the state space representation of mode - I(ON mode) and mode - II- (OFF mode) described by (3) and (4), the averaged state space representation of boost converter system is obtained and represented by the following equations:

$$
\begin{aligned}
\dot{x}= & {\left[d \cdot A_{\mathrm{I}}+(1-d) A_{\mathrm{II}}\right] x } \\
+ & {\left[d \cdot B_{\mathrm{I}}+(1-d) B_{\mathrm{II}}\right] V_{\text {input }}, } \\
V_{\text {output }}= & {\left[d \cdot C_{\mathrm{I}}+(1-d) C_{\mathrm{II}}\right] x, }
\end{aligned}
$$

where state of the switcher $d=\left\{\begin{array}{l}1 \text { in ON state } \\ 0 \text { in OFF state }\end{array}\right.$

$$
\begin{gathered}
\dot{x}=\left[\begin{array}{cc}
0 & \frac{1-d}{L} \\
-\frac{1-d}{C} & -\frac{1}{R C}
\end{array}\right] x+\left[\begin{array}{l}
\frac{d}{L} \\
0
\end{array}\right] V_{\text {input }} \\
V_{\text {output }}=\left[\begin{array}{ll}
0 & 1
\end{array}\right] x .
\end{gathered}
$$

\section{Sliding Mode Control Design}

Sliding mode is a phenomenon that may appear in a dynamic system governed by ordinary differential equations with discontinuous right-hand sides. It may happen that the control as a function of the system state switches at high frequency, and this motion is called sliding mode [22-24].

The SMC is a nonlinear control approach which complies with the nonlinear characteristic of a boost converter. Such control technique is robust even against the plant parametric variation and can compensate the modeling approximations. Also, it is characterized by a good dynamic response. In addition, the SMC is simple to implement $[25,26]$.

The first step to design a sliding mode control is to determine the sliding surface with the desired dynamics of the corresponding sliding motion. As an example, let us consider the following sliding surface $S$ :

$$
S=K_{1}\left(i_{L}-i_{L}^{*}\right)+K_{2}\left(V_{\text {output }}-V_{\text {output }}^{*}\right),
$$

where $K_{1}$ and $K_{2}$ are the sliding coefficients, $V_{\text {output }}^{*}$ is the desired output voltage, and $i_{L}^{*}$ is the desired output current.

From (6), we can deduce that at the stability point, the reference inductor current $i_{L}^{*}$ can be written as follows:

$$
i_{L}^{*}=-\frac{V_{\text {output }}^{*}}{R} \frac{\left(V_{\text {output }}^{*}-V_{\text {input }}\right)}{V_{\text {input }}} .
$$

The sliding mode control signal $d$ consists of two components, a nonlinear component $d_{n}$ and an equivalent component $d_{\mathrm{eq}}$ :

$$
d=d_{\mathrm{eq}}+d_{n}
$$

The equivalent control can be obtained when $S=\dot{S}=0$. It is expressed as follows:

$$
d_{\text {eq }}=\frac{K_{1} R C V_{\text {output }}+K_{2} L R i_{L}+K_{2} L V_{\text {output }}}{K_{2} L R i_{L}+K_{1} R C\left(V_{\text {input }}-V_{\text {output }}\right)} .
$$

The next step is to design the control input so that the state trajectories are driven and attracted toward the sliding surface and then remain sliding on it for all subsequent time. Let us consider the positive definite Lyapunov function $P$ defined as follows:

$$
P=\frac{1}{2} S^{2}
$$

The time derivative $\dot{P}$ of $P$ must be negative definite $\dot{P}<0$ to insure the stability of the system and to make the surface $S$ attractive. Such condition leads to the following inequality:

$$
\dot{P}=S \cdot \dot{S}<0 \text {. }
$$

To satisfy the condition given by the inequality (12), the nonlinear control component can be defined as follows:

$$
d_{n}=K_{3} \cdot \operatorname{sign}(S)
$$

where $K_{3}$ is negative in (13). $K_{1}$ and $K_{2}$ are chosen to be positive in (7) and (10), and the determination of these parameter were detailed in [27]. However, the major drawback of the $\mathrm{SMC}$ is the chattering phenomenon which is a consequence of the discontinuity of the nonlinear component. To overcome the disadvantage of the sliding mode control, FSMS is proposed in the next section.

\section{Fuzzy Sliding Mode Strategy Design}

The combination of the sliding mode control with the fuzzy logic control aims to improve the robustness and the performances of the controlled nonlinear systems [13, 15, 16, 22]. The proposed FSMS boost DC-DC converter control strategy scheme for the electric vehicle propulsion system is given in Figure 2.

Let us consider the sliding surface defined by (7). The proposed fuzzy sliding mode controller forces the derivative of the Lyapunov function to be negative definite. So, the rule base table is established to satisfy the inequality (12).

Intuitively, suppose that $S>0$ and $\dot{S}>0$, and then the duty cycle must increase. Also, if $S<0$ and $\dot{S}<0$, then the duty cycle must decrease. Thus, the surface $S$ and its variation $\dot{S}$ are the inputs of the proposed controller. The output signal is the control increment $\Delta U(k)$ which is used to update the control law. The control signal is defined as follows:

$$
U(k)=\Delta U(k)+U(k-1) .
$$




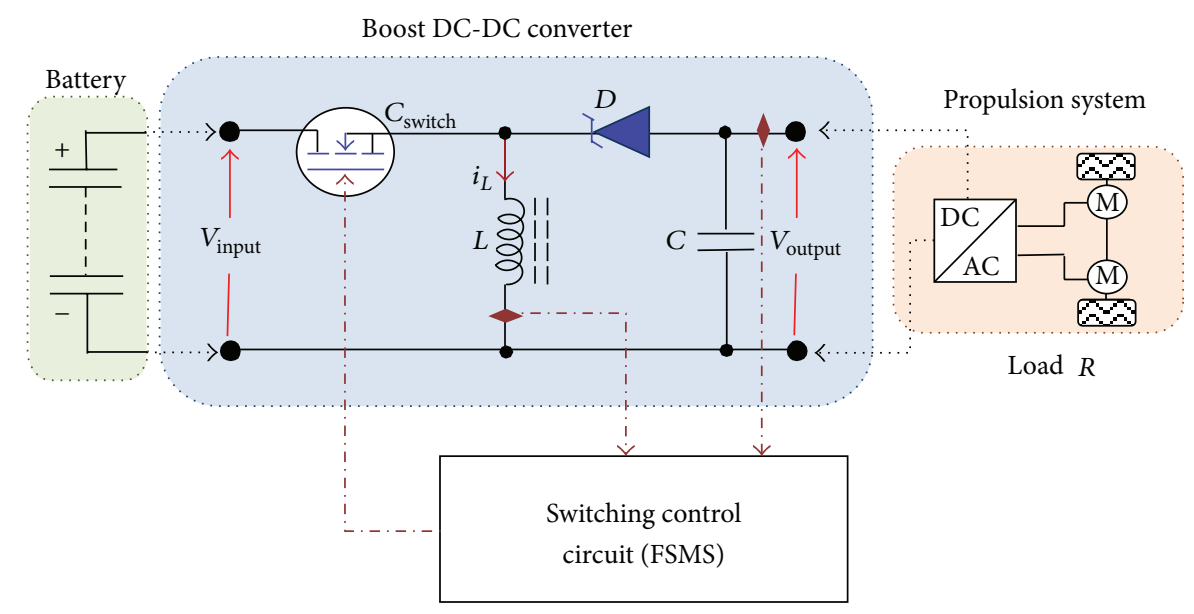

FIGURE 2: The FSMS boost DC-DC converter control strategy scheme.

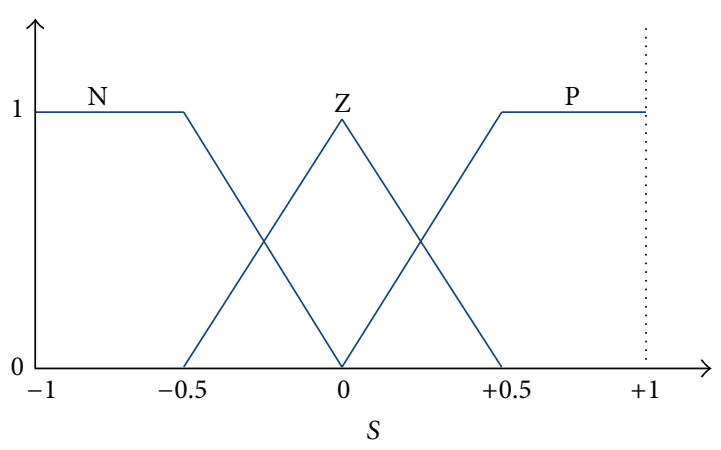

FIGURE 3: Surface $S$ membership functions.

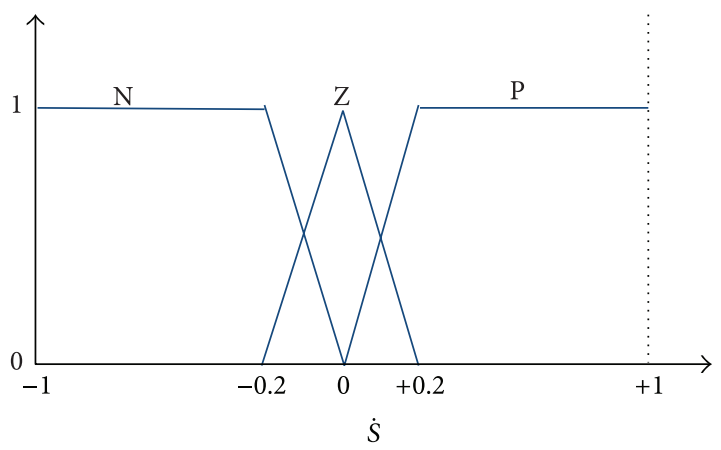

FIgURE 4: Surface change $\dot{S}$ membership functions.

The proposed fuzzy sliding mode controller is a zeroorder Sugeno fuzzy controller which is a special case of Mamdani fuzzy inference system. Only the antecedent part of the Sugeno controller has the "fuzziness," while the consequent part is a crisp function. In the Sugeno fuzzy controller, the output is obtained through the weighted average of consequents $[17,18,28]$.

Trapezoidal and triangular membership functions, denoted by $\mathrm{N}$ (Negative), Z (Zero), and P (Positive), were used for both the surface and the surface change. They are presented in Figures 3 and 4 in the normalized domain. For the output signals, fives normalized singletons denoted by

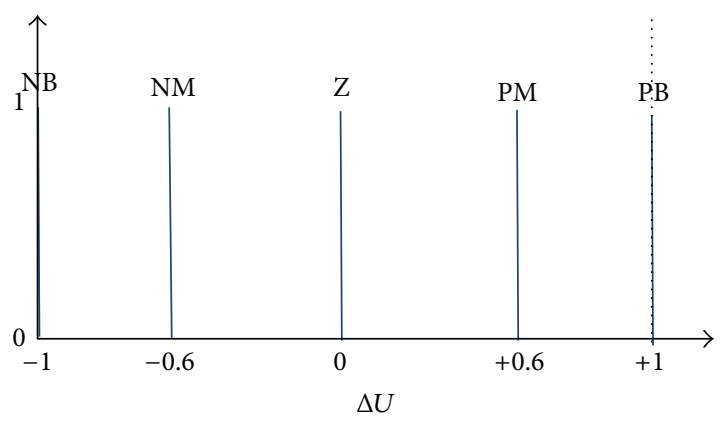

FIGURE 5: Output singletons $\Delta U$ membership functions.

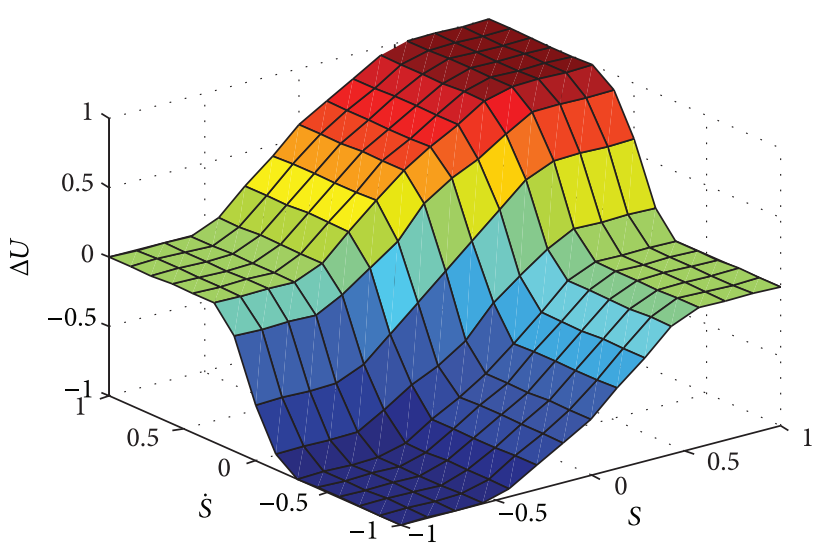

FIGURE 6: Surface plot showing the relationship between input and output parameters.

negative big $(\mathrm{NB})$, negative middle $(\mathrm{NM})$, zero $(\mathrm{Z})$, positive middle (PM), positive big (PB) are used for the output signal (Figure 5). The surface plot presentation relationship between input and output parameters of the rule table given in Table 1 is visualized in Figure 6.

Figure 7 illustrates the block diagram of fuzzy sliding mode strategy (FSMS) boost DC-DC converter control for the electric vehicle. 


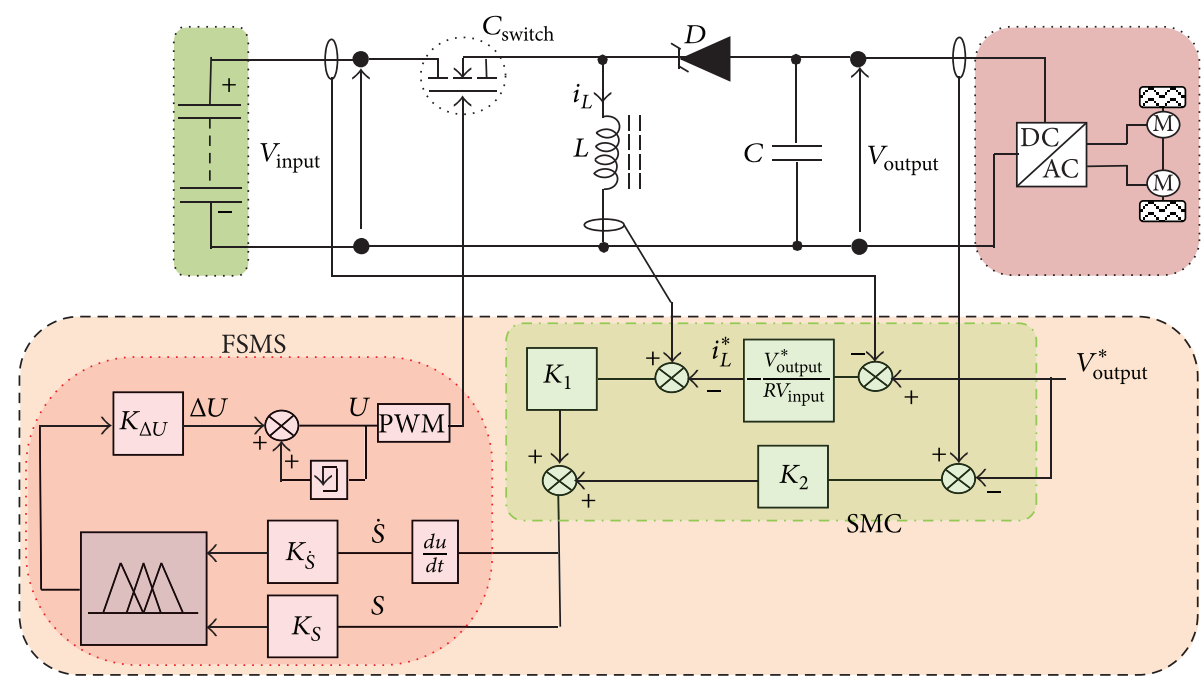

FIGURE 7: Block diagram of the FSMS boost DC-DC converter control for the electric vehicle.

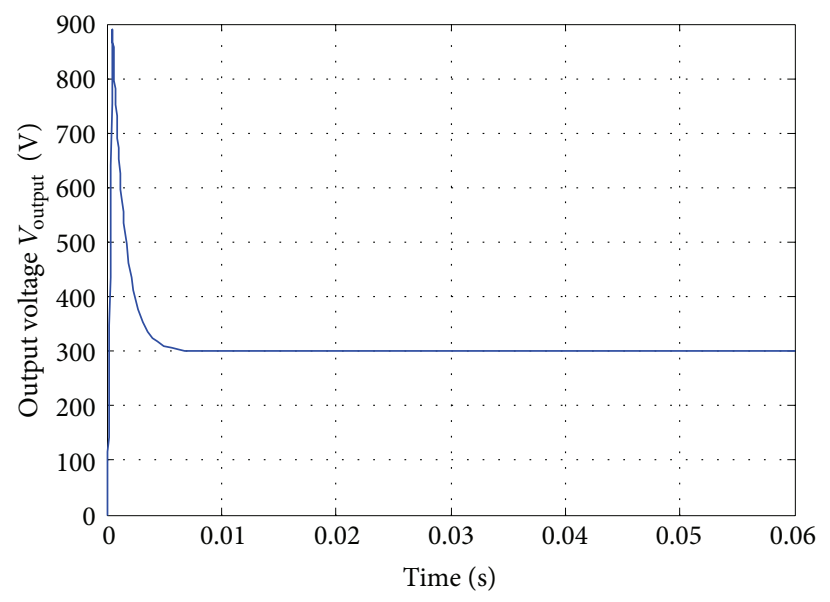

(a)

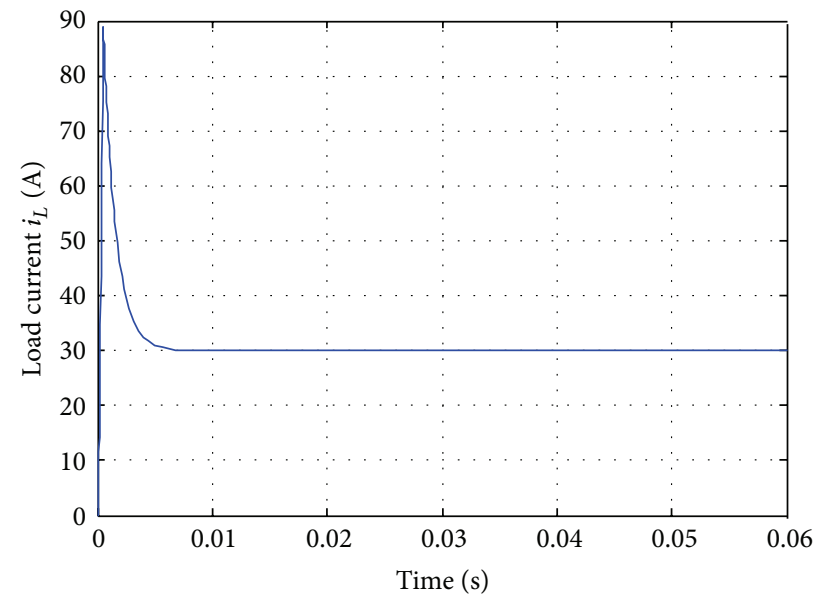

(b)

FIgURE 8: (a) The output voltage and load current open-loop responses. (b) The output voltage and load current open-loop responses.

TABLE 1: The proposed FSMS rule base.

\begin{tabular}{cccc}
\hline$\Delta U$ & & $S$ & \\
& $\mathrm{P}$ & $\mathrm{Z}$ & $\mathrm{N}$ \\
\hline$\dot{S}$ & & & \\
& $\mathrm{P}$ & $\mathrm{PB}$ & $\mathrm{Z}$ \\
$\mathrm{Z}$ & $\mathrm{PM}$ & $\mathrm{Z}$ & $\mathrm{NM}$ \\
$\mathrm{N}$ & $\mathrm{Z}$ & $\mathrm{NM}$ & $\mathrm{NB}$ \\
\hline
\end{tabular}

\section{Simulation Results}

The boost DC-DC converter used is designed for an input voltage of 10 to $72 \mathrm{~V}$ and an output voltage of 10 to $600 \mathrm{~V}$ and considered to supply a $3.5 \mathrm{~kW}$ and $300 \mathrm{~V}$ load. The electrical parameters of the simulated boost converter posed for $C=10 \mathrm{mF}, L=0.69 \mathrm{mH}$ with resistance loss equal to $0.07 \Omega . K_{1}=0.34$, and $K_{2}=0.27$ in Figure 7 .

The simulated results identified by Figures $8(\mathrm{a})$ and $8(\mathrm{~b})$ show the open-loop of the output voltage and the load current responses, respectively.

The classical SMC solution, described above, was compared to the proposed fuzzy sliding mode strategy law and also with the proportional integral (PI) controller. Figure 9 gives the simulated step responses of the studied boost converter for settling voltages $300 \mathrm{~V}$ when the input voltage is $48 \mathrm{~V}$. Figure 10 proves that the two controllers can regulate also the load current at any desired value.

From the two figures, we can conclude that the dynamical behavior of the transient state of the responses for the voltage and the current obtained by the FSMS are different. The advantage of this control is its robustness, its capacity to maintain ideal reference trajectories for output voltage boost DC-DC converter control and ensure good disturbances 

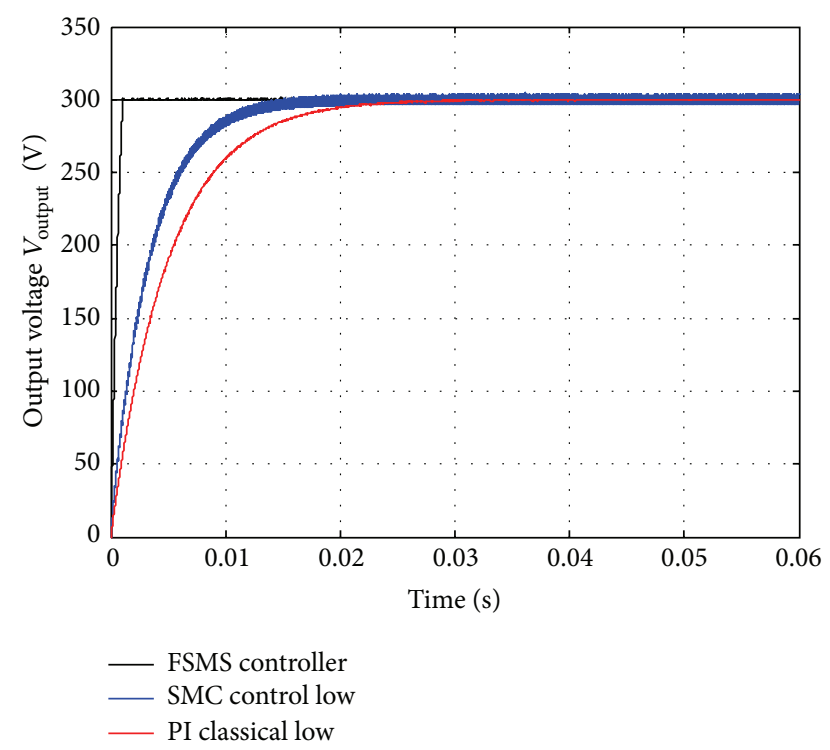

FIGURE 9: Step voltage responses of the boost DC-DC converter by the application of the SMC, FSMS, and PI controller.

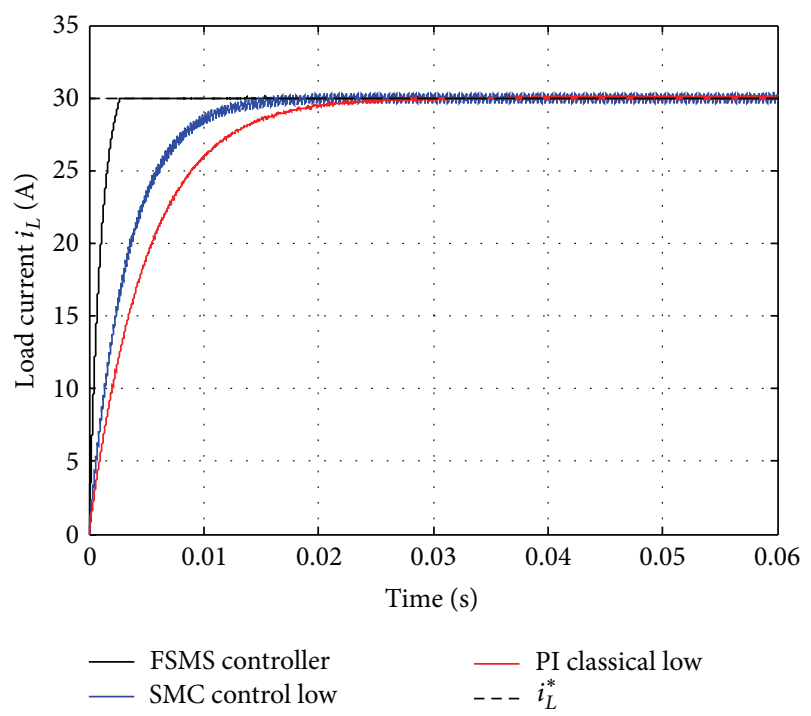

FIGURE 10: Step current responses of the boost converter by the application of the SMC, FSMS, and PI controller.

rejections with no overshoot, and stability of DC-DC converter ensured with the output voltage variation and less error output voltage.

The simulated results, specified by Figures 11 and 12, prove that the chattering phenomenon was reduced from the output voltage response and the load current of the boost DC-DC converter by the application of the FSMS. As well, the next simulations test the robustness of the FSMS for the case of the load current variation and the input voltage variation. Figure 13 presents the variation of the current from $30 \mathrm{~A}$ to $45 \mathrm{~A}$ at $0.02 \mathrm{~s}$. We can notice in Figure 14 that FSMS rejects such perturbation.

From Figures 15, 16, 17, 18, 19, 20, and 21, we test the boost DC-DC converter when the input varies (battery state of

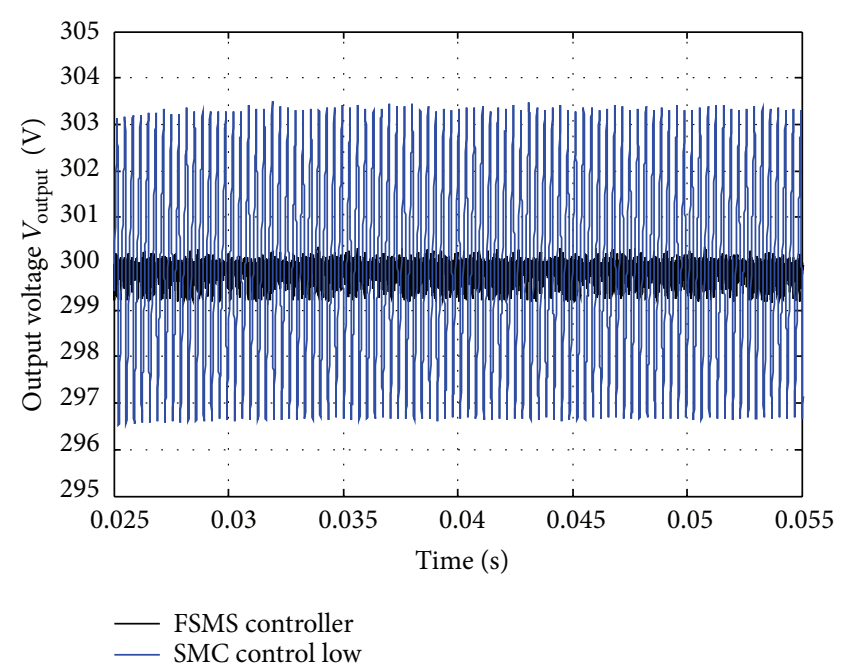

FIGURE 11: Chattering phenomenon reduction from the output voltage response.

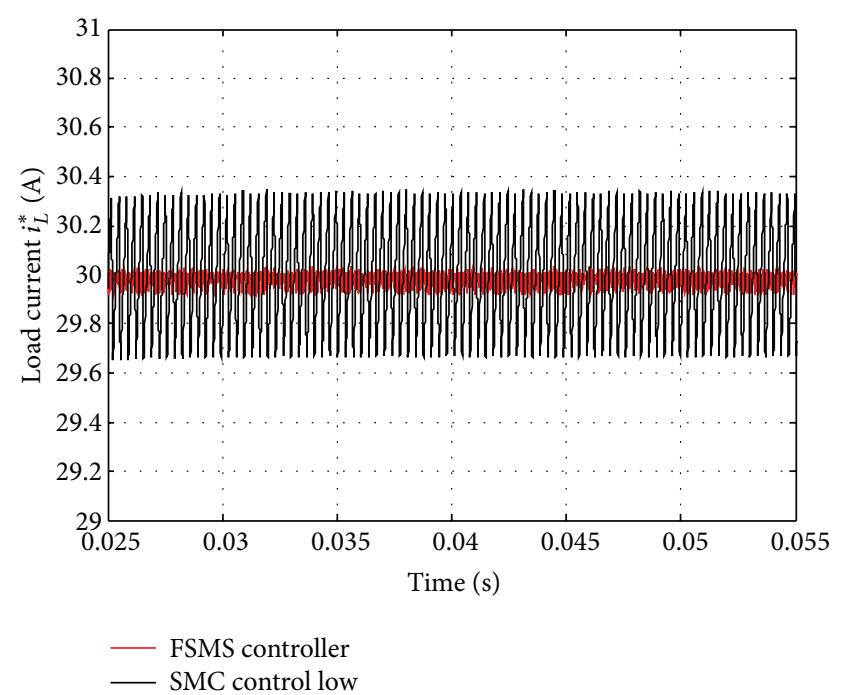

FIGURE 12: Chattering phenomenon reduction from the load current response.

charge varies). Figure 15 illustrates the variation of the input voltage from $48 \mathrm{~V}$ to $35 \mathrm{~V}$ at $0.02 \mathrm{~s}$. For such case, we notice that the output voltage is always at the desired value $300 \mathrm{~V}$ and the converter work as boost one.

In Figure 18, the input voltage varies from $61 \mathrm{~V}$ to $48 \mathrm{~V}$ at $0.02 \mathrm{~s}$. Figure 19 proves that the output voltage still at the same desired value $(300 \mathrm{~V})$. For this simulation, the converter working mode boosts.

\section{Conclusion}

The research outlined in this paper has demonstrated the robustness and the dynamical performances for electric vehicle boost DC-DC converter by using the fuzzy sliding mode strategy. In the present study, we propose a FSMS for improving the control robustness. The proposed fuzzy logic 


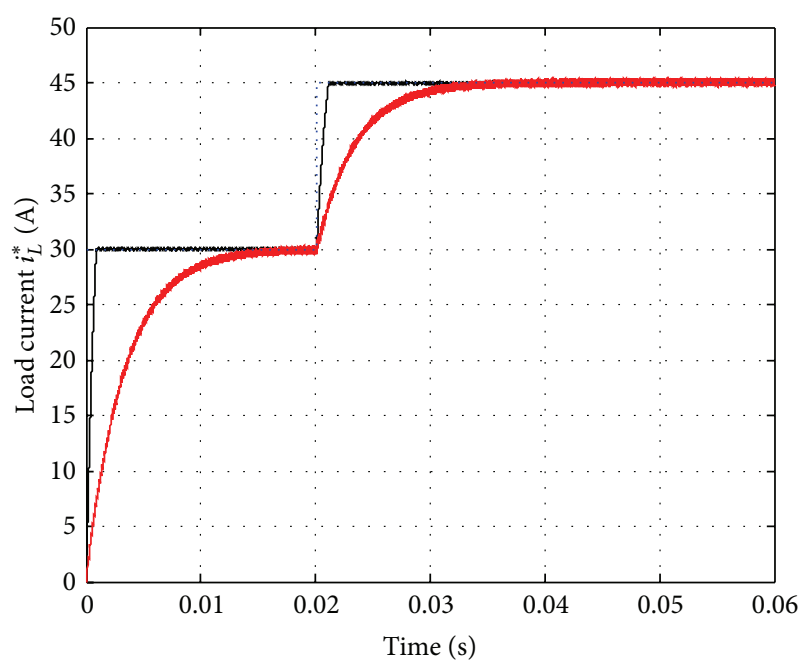

- FSMS controller

— SMC control low $\ldots \ldots i_{L}^{*}$

FIGURE 13: Variation of the load current from $30 \mathrm{~A}$ to $45 \mathrm{~A}$.

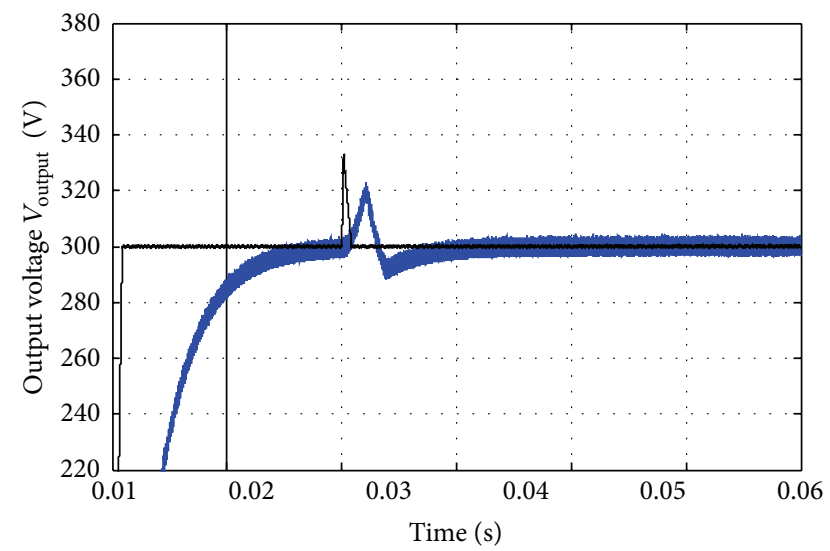

FSMS controller

SMC control low

FIGURE 14: Robustness test of the FSMS for the variation of the load current from $30 \mathrm{~A}$ to $45 \mathrm{~A}$.

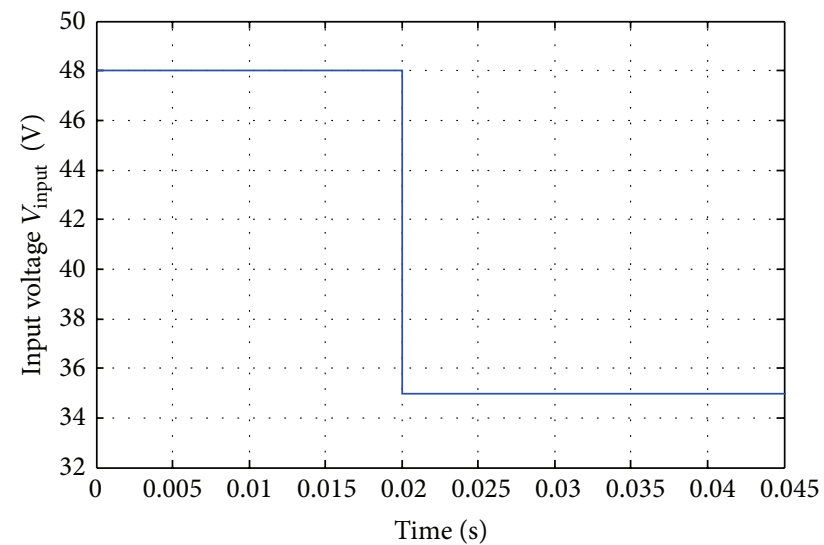

Figure 15: Evolution of the input voltage from $48 \mathrm{~V}$ to $35 \mathrm{~V}$.

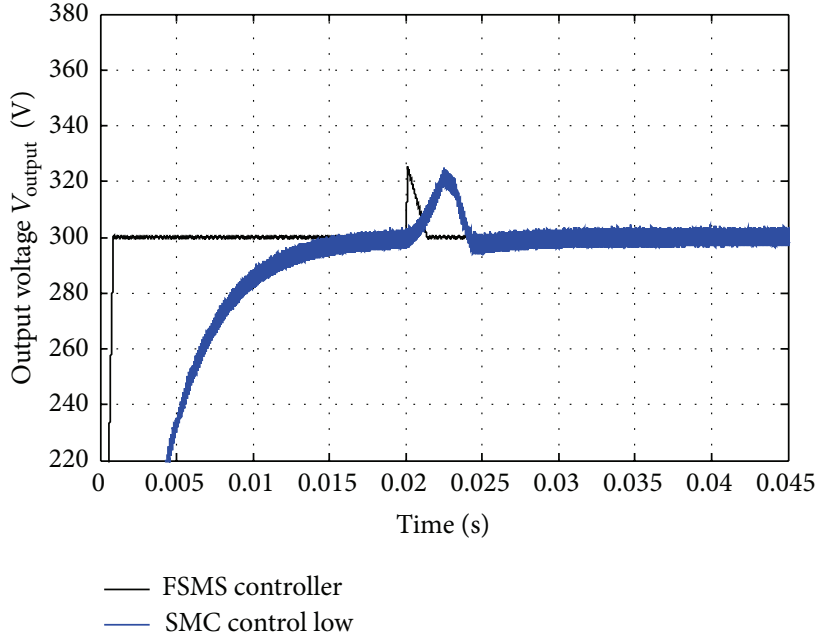

FIGURE 16: Robustness test of the FSMS for the variation of the input voltage from $48 \mathrm{~V}$ to $35 \mathrm{~V}$.

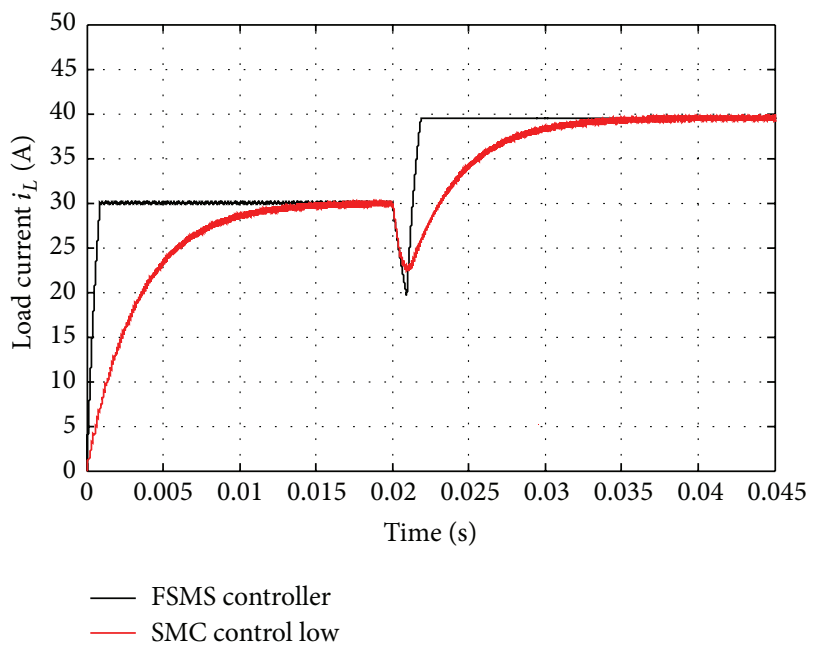

FIGURE 17: Evolution of the load current when the input voltage changes from $48 \mathrm{~V}$ to $35 \mathrm{~V}$.

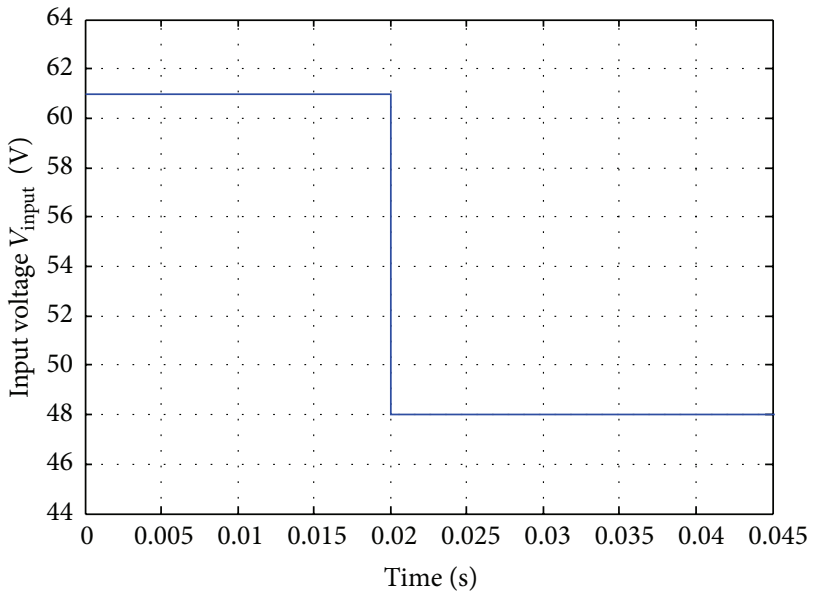

FIGURE 18: Evolution of the input voltage from $61 \mathrm{~V}$ to $48 \mathrm{~V}$. 


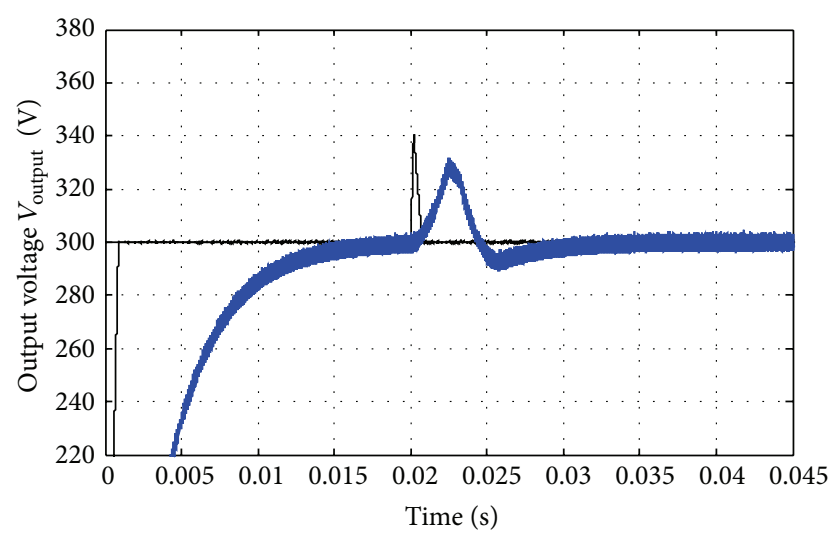

- FSMS controller

— SMC control low

FIGURE 19: Robustness test of the FSMS for the variation of the input voltage from $61 \mathrm{~V}$ to $48 \mathrm{~V}$.

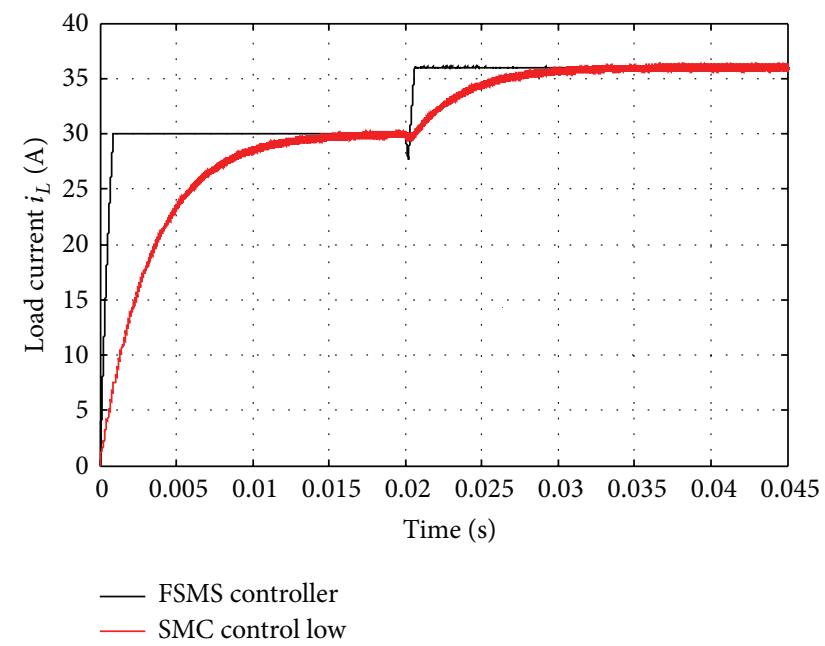

FIGURE 20: Evolution of the load current when $t$ the input voltage changes from $61 \mathrm{~V}$ to $48 \mathrm{~V}$.

controller has as inputs the sliding surface and its variation. It defines the control signal to satisfy the stability and the attraction condition of the sliding surface. The proposed FSMS simulation results show that the proposed controller overcomes the chattering problem. Moreover, it has proven that the proposed controller is robust for the case of the desired output currents variation caused by propulsion system load variation of the electric vehicle and the input voltage variations caused by charge/discharge batteries effects. The disturbances do not affect the performances of the boost DC-DC converter output voltage, and the control strategy gives good dynamic characteristics of the electric vehicle propulsion system load.

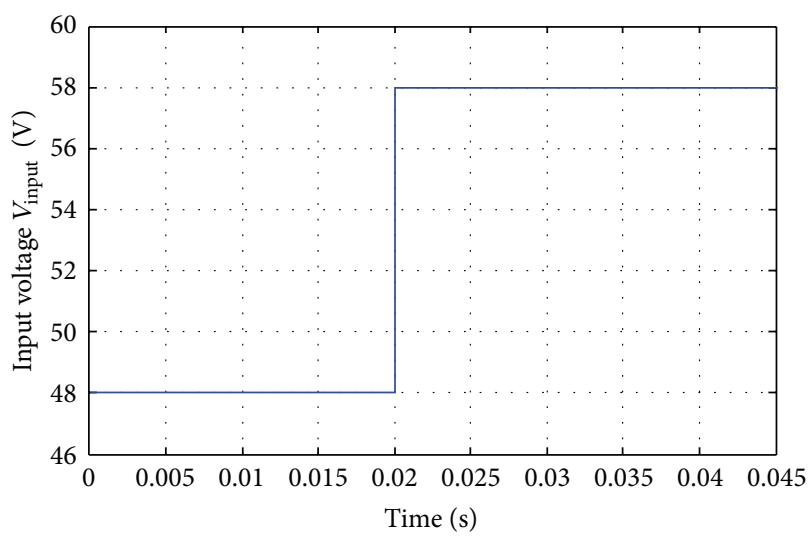

FIgURE 21: Evolution of the input voltage from $48 \mathrm{~V}$ to $58 \mathrm{~V}$.

\section{References}

[1] J. Moreno, J. Dixon, and M. Ortuzar, "Energy management system for an electric vehicle, using ultracapacitors and neural networks," IEEE Transactions on Industrial Electronics, vol. 53, no. 2, pp. 614-623, 2006.

[2] M. Salman, M. Chang, and J. Chen, "Predictive energy management strategies for hybrid vehicles," in Proceedings of the IEEE Conference Vehicle Power and Propulsion, pp. 21-25, Chicago, Ill, USA, September 2005.

[3] J. Larminie and J. Lowry, Electric Vehicle Technology Explained, John Wiley \& Sons, England, UK, 2003.

[4] R. F. Nelson, "Power requirements for battery in HEVs," Journal of Power Sources, vol. 91, pp. 2-26, 2000.

[5] M. Rashid, Power Electronics Handbook, Elsevier Press, 2007.

[6] C. Xia and Y. Guo, "Implementation of a Bi-directional DC/DC Converter in the electric vehicle," Journal of Power Electronics, vol. 40, no. 1, pp. 70-72, 2006.

[7] X. X. Yan and D. Patterson, "Novel power management for high performance and cost reduction in an electric vehicle," Renewable Energy, vol. 22, no. 1-3, pp. 177-183, 2001.

[8] Q. Zhang and Y. Yin, "Analysis and evaluation of bidirectional DC/DC converter," Journal of Power Technology, vol. 1, no. 4, pp. 331-338, 2003.

[9] S. Buso, "Design of a robust voltage controller for a Buck-Boost converter using $\mu$-synthesis," IEEE Transactions on Control Systems Technology, vol. 7, no. 2, pp. 222-229, 1999.

[10] Y. B. Shtessel, A. S. I. Zinober, and I. A. Shkolnikov, "Sliding mode control of boost and buck-boost power converters using method of stable system centre," Automatica, vol. 39, no. 6, pp. 1061-1067, 2003.

[11] S. C. Tan, Y. M. Lai, and C. K. Tse, "An evaluation of the practicality of sliding mode controllers in DC-DC converters and their general design issues," in Proceedings of the 37th IEEE Power Electronics Specialists Conference, pp. 187-193, 2006.

[12] S. C. Tan, Y. M. Lai, and C. K. Tse, "A unified approach to the design of PWM-based sliding-mode voltage controllers for basic DC-DC converters in continuous conduction mode," IEEE Transactions on Circuits and Systems I, vol. 53, no. 8, pp. 1816-1827, 2006.

[13] F. Song and S. M. Smith, "A comparison of sliding mode controller and fuzzy sliding mode controller," in Proceedings of the 19th International Conference of the North American Fuzzy Information Processing Society (NAFIPS '00), pp. 480-484, 2000. 
[14] S. B. Choi, C. C. Cheong, and D. W. Park, "Moving switching surfaces for robust control of second order variable structure systems," International Journal of Control, vol. 58, no. 1, pp. 229245, 1993.

[15] Q. P. Ha, D. C. Rye, and H. F. Durrant-Whyte, "Fuzzy moving sliding mode control with application to robotic manipulators," Automatica, vol. 35, no. 4, pp. 607-616, 1999.

[16] H. Lee, E. Kim, H. Kang, and M. Park, "Design of sliding mode controller with fuzzy sliding surfaces," IEE Proceedings Control Theory \& Applications, vol. 145, no. 5, 1998.

[17] H. Temeltas, "A fuzzy adaptation technique for sliding mode controllers," in Proceedings of the IEEE International Symposium on Intelligent Control, pp. 15-18, Columbus, Ohio, USA, 1994.

[18] S. W. Kim and J. J. Lee, "Design of a fuzzy controller with fuzzy sliding surface," Fuzzy Sets and Systems, vol. 71, pp. 359-367, 1995.

[19] Q. Zhao and F. C. Lee, "High efficiency, high step-up DC-DC converters," IEEE Transactions on Power Electronics, vol. 18, pp. 65-73, 2003.

[20] H. J. Chill and L. W. Lin, "A bidirectional DC-DC converter for fuel cell electric vehicle driving system," IEEE Transactions on Power Electronics, vol. 21, pp. 950-958, 2006.

[21] M. Ehsani, K. M. Rahman, M. D. Bellar, and A. J. Severinsky, "Evaluation of soft switching for EV and HEV motor drives," IEEE Transactions on Industrial Electronics, vol. 48, no. 1, pp. 82-90, 2001.

[22] A. Nasri, A. Hazzab, I. K. Bousserhane, S. Hadjeri, and P. Sicard, "Fuzzy-sliding mode speed control for two wheels electric vehicle drive," Journal of Electrical Engineering \& Technology, vol. 4, no. 4, pp. 499-509, 2009.

[23] K. D. Young, V. I. Utkin, and U. Ozguner, "A control engineer's guide to sliding mode control," IEEE Transactions on Control Systems Technology, vol. 7, no. 3, pp. 328-342, 1999.

[24] C. Edwards and S. L. Spurgeon, Sliding Mode Control: Theory and Applications, Taylor \& Francis, London, UK, 1998.

[25] C. K. Tse and K. M. Adams, "Quasi-linear analysis and control of DC-DC converters," IEEE Transactions on Power Electronics, vol. 7, no. 2, pp. 315-323, 1992.

[26] V. M. Nguyen and C. Q. Lee, "Indirect implementations of sliding-mode control law in buck-type converters," in Proceedings of the IEEE Applied Power Electronics Conference, vol. 1, pp. 111115, Mars 1996.

[27] H. El Fadil and F. Giri, "Reducing chattering phenomenon in sliding mode control of Buck-Boost power converters," in Proceedings of the IEEE International Symposium on Industrial Electronics (ISIE '08), pp. 287-292, July 2008.

[28] M. K. Passino, Fuzzy Control, Addison-Wesley, London, UK, 2000. 

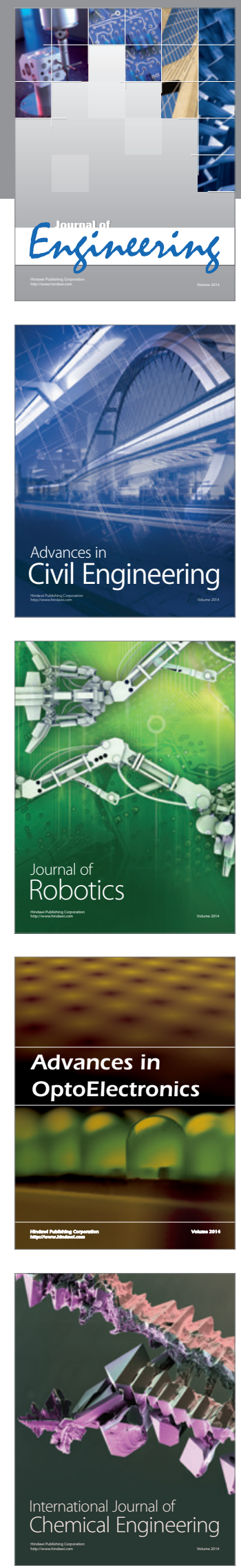

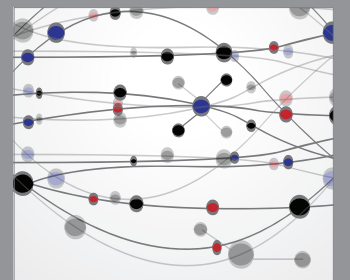

The Scientific World Journal
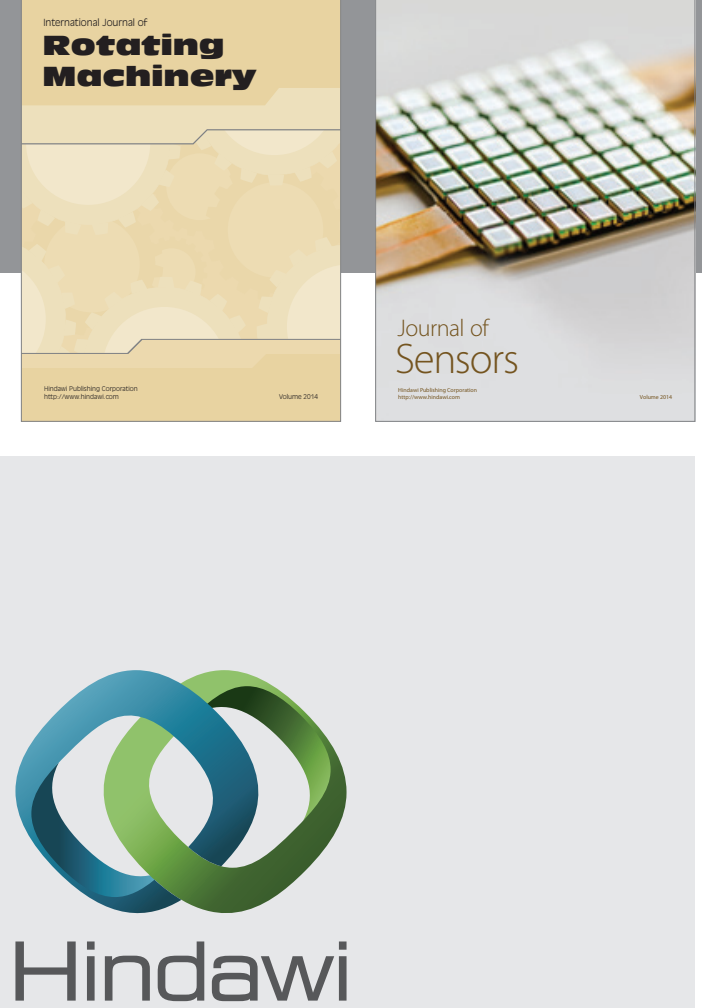

Submit your manuscripts at http://www.hindawi.com
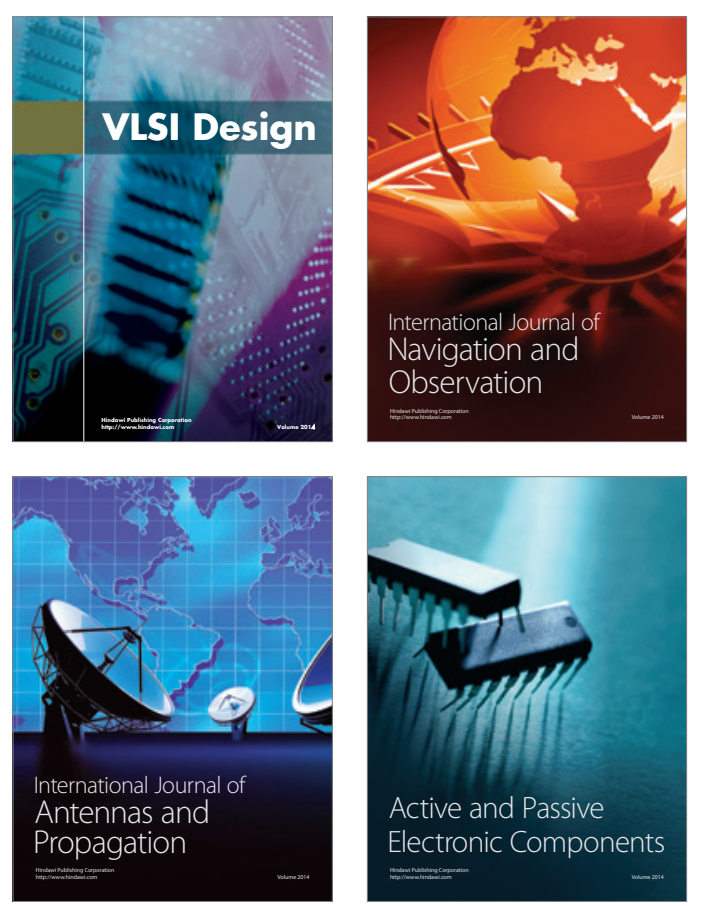
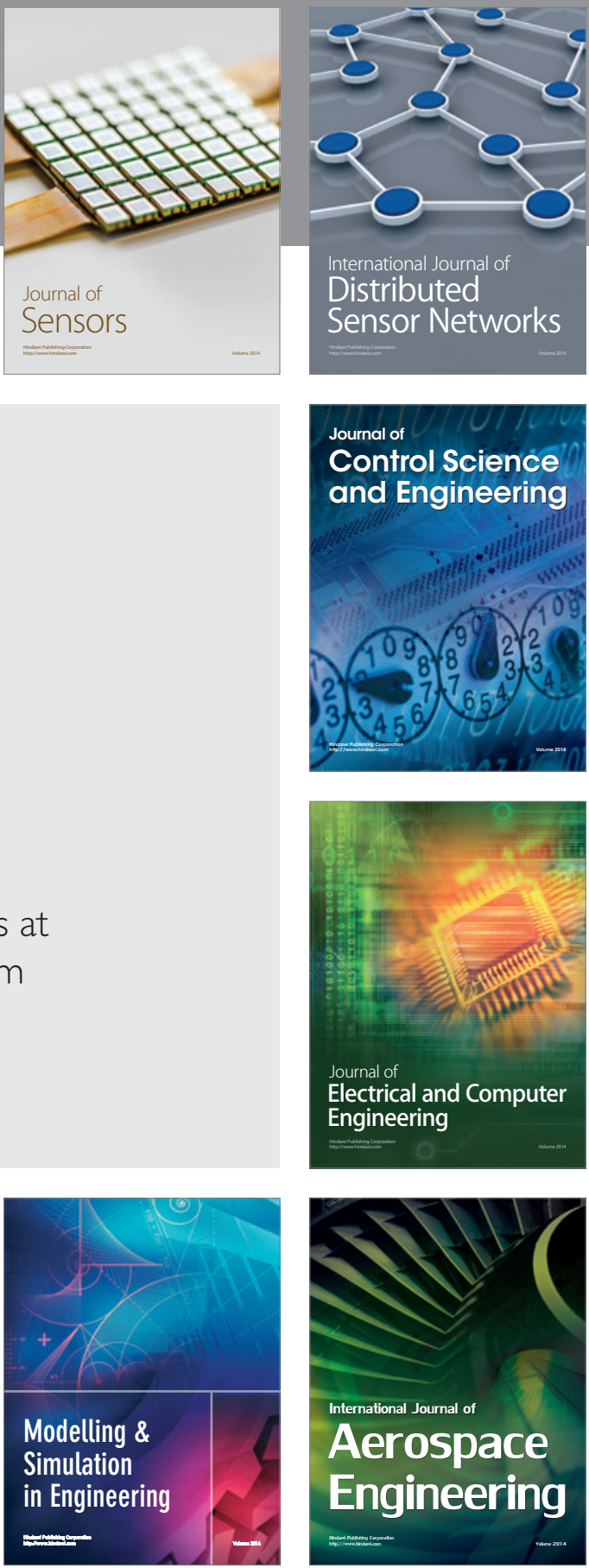

Journal of

Control Science

and Engineering
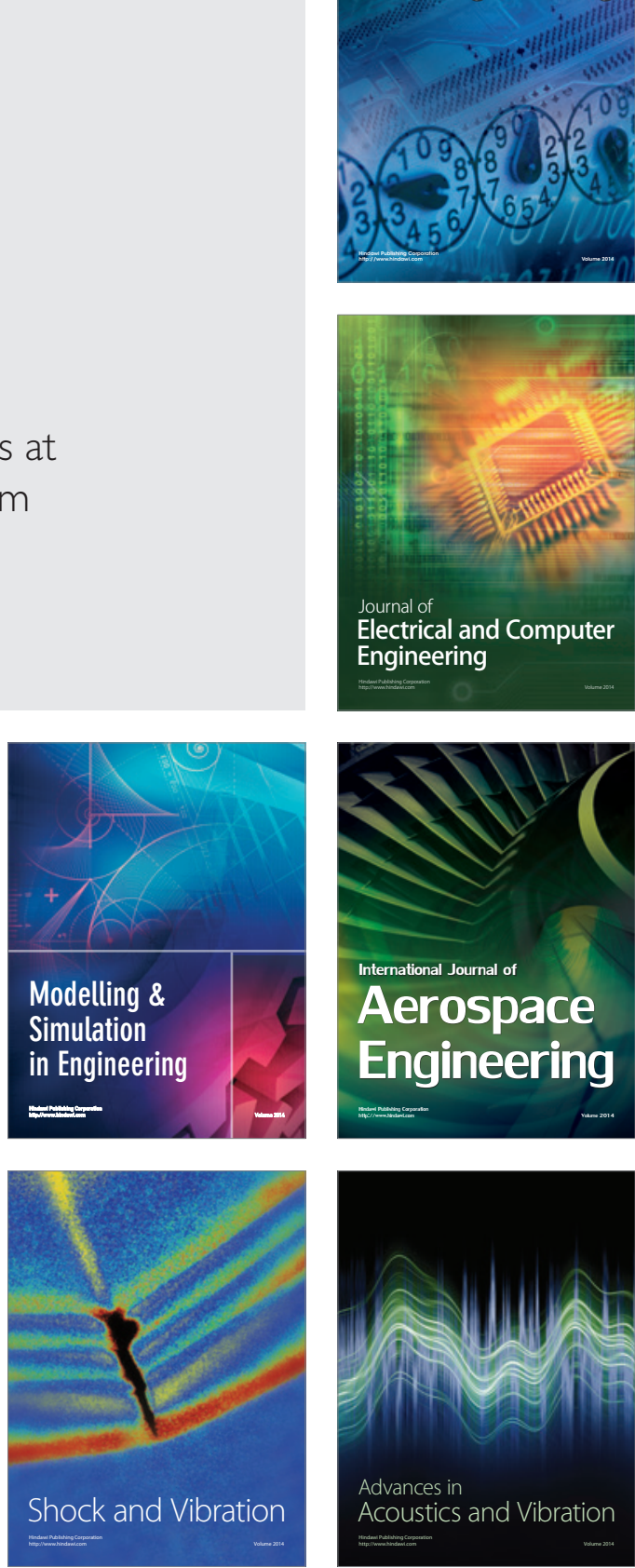